Brief report

\title{
Shared reduction of oscillatory natural frequencies in bipolar disorder, major depressive disorder and schizophrenia
}

\author{
Paola Canali ${ }^{\text {a,* }}$, Simone Sarasso ${ }^{\mathrm{b}}$, Mario Rosanova ${ }^{\mathrm{b}, \mathrm{e}}$, Silvia Casarotto ${ }^{\mathrm{b}}$, \\ Giovanna Sferrazza-Papa ${ }^{a}$, Olivia Gosseries ${ }^{\mathrm{c}, \mathrm{d}}$, Matteo Fecchio ${ }^{\mathrm{b}}$, Marcello Massimini ${ }^{\mathrm{b}}$, \\ Maurizio Mariotti ${ }^{\mathrm{b}}$, Roberto Cavallaro ${ }^{\text {, }}$ Enrico Smeraldi ${ }^{\mathrm{a}}$, Cristina Colombo ${ }^{\mathrm{a}}$, \\ Francesco Benedetti ${ }^{a}$ \\ a Department of Clinical Neurosciences, Scientific Institute Ospedale San Raffaele and University Vita-Salute San Raffaele, Milano, Italy \\ b Department of Biomedical and Clinical Sciences "L. Sacco", Università degli Studi di Milano, Italy \\ ' Coma Science Group, Cyclotron Research Centre and Neurology Department, University and University Hospital of Liegi, Belgium \\ d Center for Sleep and Consciousness and Postle Laboratory, Department of Psychology and Psychiatry, University of Wisconsin, Madison, WI, USA \\ e Fondazione Europea di Ricerca Biomedica, ONLUS Milan, Italy
}

\section{A R T I C L E I N F O}

Article history:

Received 16 January 2015

Received in revised form

20 May 2015

Accepted 22 May 2015

Available online 3 June 2015

Keywords:

TMS/EEG

Gamma oscillations

Neuropsychiatric disorders

GABAergic circuits

\begin{abstract}
A B S T R A C T
Introduction: Recent studies have demonstrated that cortical brain areas tend to oscillate at a specific natural frequency when directly perturbed by transcranial magnetic stimulation (TMS). Fast electroencephalographic (EEG) oscillations, which typically originate from frontal regions, have been reported to be markedly reduced in schizophrenia.

Methods: Here we employed TMS/EEG to assess the natural frequency of the premotor area in a sample of 48 age-matched participants (12 each in major depression disorder (MDD)), bipolar disorder (BPD), schizophrenia (SCZ) and healthy controls. Event related spectral perturbations (ERSP) were obtained for each study participant using wavelet decomposition.

Results: TMS resulted in a significant activation of the beta/gamma band response (21-50 Hz) to frontal cortical perturbation in healthy control subjects. By contrast, the main frequencies of frontal EEG responses to TMS were significantly reduced in patients with BPD, MDD and SCZ (11-27 Hz) relative to healthy subjects.

Conclusions: Patients with bipolar disorder, major depression and schizophrenia showed a significantly lower natural frequency of frontal cortico-thalamocortical circuits compared to healthy controls. These results suggest a common neurobiological mechanism of corticothalamic impairment. The most likely candidates include dysfunction of GABAergic circuits.

Limitations: Further studies are needed to consider other biological markers, gene variants, and their interaction with clinical variables.
\end{abstract}

(c) 2015 Elsevier B.V. All rights reserved.

\section{Introduction}

High-frequency gamma oscillations are critical for communication among brain areas, thus allowing integration among cortical modules (Nikolic et al., 2013; Rodriguez et al., 1999; Whittington et al., 2000b). In the last decade clinical research on oscillatory brain dynamics reported altered neuronal oscillations in neuropsychiatric disorders (Basar, 2013; Basar and Guntekin, 2008; Herrmann and Demiralp, 2005; Uhlhaas and Singer, 2010),

\footnotetext{
* Correspondence to: Istituto Scientifico Universitario Ospedale San Raffaele, Dipartimento di Neuroscienze Cliniche, San Raffaele Turro, Via Stamira d'Ancona 20 20127, Milano, Italy. Tel.: + 390226433156.

E-mail address: canali.paola@gmail.com (P. Canali).
}

suggesting that reduced gamma oscillations could be common to bipolar disorder (BPD), major depressive disorder (MDD) and schizophrenia (SCZ) (Maharajh et al., 2007; O'Donnell et al., 2004b).

Frontal cortical gamma activity (30-50 HZ), as indexed through electroencephalography (EEG), is reduced in patients with SCZ (Uhlhaas et al., 2008), in response to odd-ball paradigm (Gallinat et al., 2004; Haig et al., 2000; Symond et al., 2005) or cognitive control task (Cho et al., 2006). EEG power and phase synchronization in beta/gamma frequencies bands after to $40 \mathrm{~Hz}$ auditory stimulation are also reduced (Kwon et al., 1999; Light et al., 2006). Findings in mood disorders are similar. BPD patients in the manic or mixed state show hampered auditory EEG synchronization in beta/gamma band $(20-50 \mathrm{~Hz})$ during a click trains paradigm 
(O'Donnell et al., 2004a), and reported significantly reduced long distance gamma coherence in a visual odd-ball paradigm (Ozerdem et al., 2010). A recent study reported a decrease of frontal gamma oscillations in patients with MDD and BPD in response to implicit emotional tasks (Lee et al., 2010; Liu et al., 2012). A reduced phase locking and evoked power at $40-\mathrm{Hz}$ auditory steady-state stimulation in first episode psychosis of patients with either schizophrenia or affective disorders has also been reported (Spencer et al., 2008).

The combination of transcranial magnetic stimulation with high-density electroencephalographic recording (TMS/EEG) represents a provocative approach useful to identify the integrity of thalamocortical circuits by directly challenging the brain's capacity to produce and sustain oscillatory activity (Buzsaki and Watson, 2012; Canali, 2014; Rosanova et al., 2012). By combining TMS/EEG we previously demonstrated that each cortical region perturbed by TMS tend to oscillate at specific natural frequency (Rosanova et al., 2009), and we found a deficit in the oscillatory properties in schizophrenia resulting in a reduction of frontal natural frequencies (Ferrarelli et al., 2008; Ferrarelli et al., 2012). Here we hypothesized impairments of the thalamocortical system to produce fast oscillations in bipolar disorder and major depression. We then aimed at investigating the oscillatory properties of the premotor cortex by employing TMS/EEG in two groups of patients with bipolar disorder and major depression, and using a group of healthy subjects as negative controls and a group of patients with schizophrenia as positive controls.

\section{Methods}

We studied 12 healthy subjects as controls (HC), and 36 consecutively admitted inpatients suffering from three different psychiatric disorders (DSM-IV criteria, SCID interview): either major depressive episode, without psychotic features, in course of BPD $(n=12)$ or in course of MDD $(n=12)$, or chronic undifferentiated schizophrenia $(n=12)$. Inclusion criteria were the absence of other diagnoses on axis I and of mental retardation on axis II; absence of pregnancy, history of epilepsy, or major medical and neurologic disorders; absence of a history of drug or alcohol dependency or abuse within the last 6 months. Six BPD were taking lithium salts. All MDD patients were on antidepressant treatment, also with benzodiazepines $(n=8)$ or mood stabilizers $(n=3)$. SCZ patients were taking antipsychotics (typical neuroleptics: $n=5$; a typical antipsychotics: $n=7$ ). A written informed consent was obtained for all study participants. The local ethics committee approved the experimental protocol.

The experimental setup included a TMS compatible 60-channel EEG amplifier (Nexstim) equipped with sample-and-hold circuits that prevents the recording from the powerful TMS-related artifact (Virtanen et al., 1999). Accuracy and reproducibility of TMS/EEG responses were controlled with a Navigated Brain Stimulation (NBS) system (Nexstim) and a 3D-infrared Tracking Position Sensor Unit (Northem Digital Inc). (For details of methods, see Rosanova et al. (2009) and Supplementary materials.)

TMS was delivered on the convexity of the middle caudal portion of the superior frontal gyrus close to the midline (Broadmann's areas 6), with the current perpendicular to its main axis. To ensure significant EEG responses (Casali et al., 2010; Komssi et al., 2007; Rosanova et al., 2009) intensity of TMS induced electric field was always $>90 \mathrm{~V} / \mathrm{m}$ as estimated by the NBS system, for each study participant. We delivered about 200-300 stimuli for each session at a frequency randomly jittered between 1.5 and $1.8 \mathrm{~s}$ (equivalent to about $0.5-0.6 \mathrm{~Hz}$ ). (See Supplementary for detailed description.)
Data analysis was carried out using Matlab (The Mathworks Inc.) with the EEGLAB toolbox (Delorme and Makeig, 2004). Each TMS-evoked response was obtained by averaging 150-250 artifact free trials. (For detailed TMS-evoked potential acquisition and analyses, see Casali et al. (2010) and Supplementary materials.)

In order to quantify the responses in the time-frequency domain (Delorme and Makeig, 2004), from each TMS/EEG session, we measured the event-related spectral perturbation (ERSP) changes in the power spectrum using wavelet decomposition (3.5 oscillation cycles) across single-trials at the channel closest to the stimulation site. The ERSP was normalized by subtracting the mean baseline power spectrum. Significant ERSP were evaluated by applying a bootstrap statistical method based on a surrogate distribution randomly derived from the pre-stimulus onset (ranging from -700 to $-50 \mathrm{~ms}$ ). Statistical significance level was set at $p<0.01$ and only significant values were considered in the analysis. Averaged ERSP values across all trials of a session were calculated between 8 and $50 \mathrm{~Hz}$ ( $1 \mathrm{~Hz}$ bin resolution) over a 20300 milliseconds time window, corresponding to the main EEG activity evoked by TMS. The natural frequency was computed as the frequency bin with the largest cumulated ERSP over time (Rosanova et al., 2009). Differences between the frontal natural frequencies of the four study groups were analyzed with one-way ANOVA followed by post-hoc Newman-Keuls's tests. Pearson correlation analysis between medications doses, clinical variables and natural frequency were performed. Analyses were carried out using a commercial available software (StatSoft Statistica) and following standard computational procedures (Hill and Lewicki, 2006).

\section{Results}

Clinical and demographic characteristics of the sample divided according to diagnosis, and the evoked natural frequencies, are resumed in Table 1.

All four groups were closely age-matched. Patients with bipolar or unipolar depression had a similar age at onset and duration of illness and did not differ on the Hamilton Depression Rating Scale (HDRS) score. Patients with schizophrenia reported positive and negative symptoms as measured by PANSS.

Data obtained with the TMS/EEG procedure are resumed in Fig. 1.

Table 1

Demographic and Clinical Characteristics of the study groups ${ }^{\text {a }}$.

\begin{tabular}{|c|c|c|c|c|c|c|}
\hline & $\begin{array}{l}\text { Healthy } \\
\text { subjects }\end{array}$ & $\begin{array}{l}\text { Bipolar } \\
\text { disorder }\end{array}$ & $\begin{array}{l}\text { Major } \\
\text { depression }\end{array}$ & Schizophrenia & $F$ & $P$ \\
\hline Gender $(\mathrm{m} / \mathbf{f})$ & $5 / 7$ & $2 / 10$ & $4 / 8$ & $9 / 3$ & & \\
\hline Age (yrs) & $39(15)$ & $36(7)$ & $46(8)$ & $38(9)$ & 2.1 & 0.1 \\
\hline $\begin{array}{l}\text { Age at onset } \\
\text { (yrs) }\end{array}$ & & $25(6)$ & $29(9)$ & $25(6)$ & 1.1 & 0.3 \\
\hline $\begin{array}{l}\text { Duration of } \\
\text { illness (yrs) }\end{array}$ & & $11(9)$ & $18(10)$ & $13(6)$ & 0.1 & 0.1 \\
\hline $\begin{array}{l}\text { PANSS } \\
\text { (positive) }\end{array}$ & & & & $18(4)$ & & \\
\hline $\begin{array}{l}\text { PANSS } \\
\text { (negative) }\end{array}$ & & & & $18(4)$ & & \\
\hline $\begin{array}{l}\text { PANSS } \\
\text { (general) }\end{array}$ & & & & $37(5)$ & & \\
\hline $\begin{array}{l}\text { HDRS } \\
\text { (baseline) }\end{array}$ & & $26(6)$ & $24(7)$ & & 1.1 & 0.8 \\
\hline $\begin{array}{l}\text { Frontal natural } \\
\text { frequency } \\
(\mathrm{Hz})\end{array}$ & $\begin{array}{l}27.25 \\
(3.22)\end{array}$ & $\begin{array}{l}20.30 \\
(3.72)\end{array}$ & $19.24(5.03)$ & $20.30(4.22)$ & & \\
\hline
\end{tabular}

${ }^{a}$ Values are expressed as mean and standard deviations. 

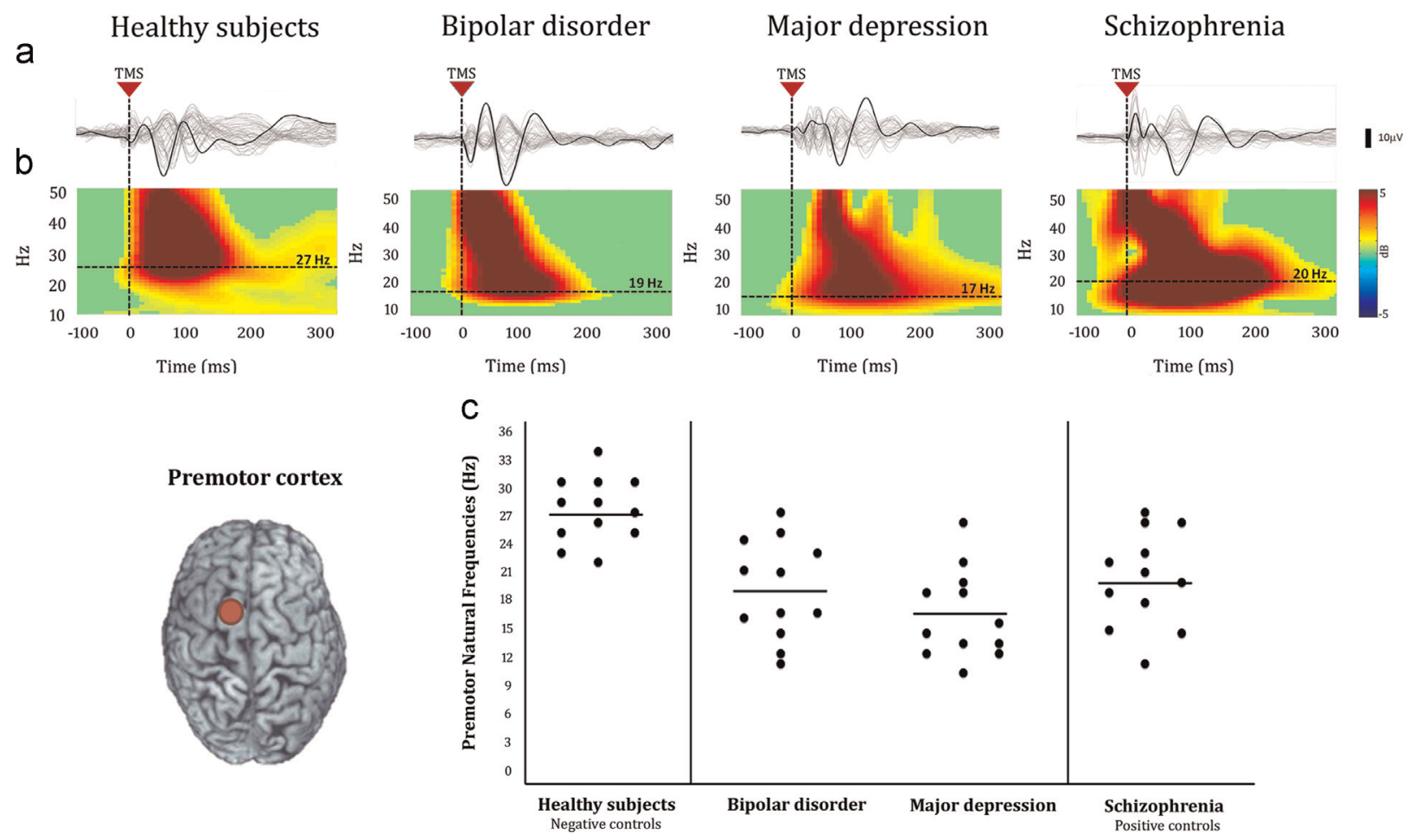

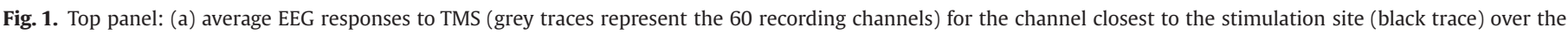

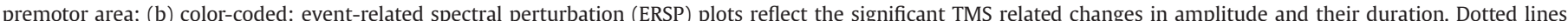

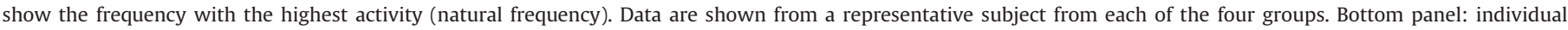

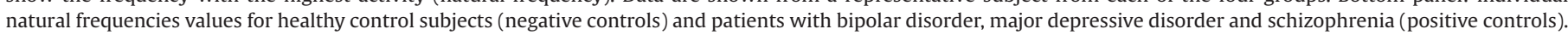
(For interpretation of the references to color in this figure legend, the reader is referred to the web version of this article.)

TMS significantly activated the beta/gamma band response (range $21-50 \mathrm{~Hz}$ ) to frontal cortical perturbation in HC. The main frequencies of frontal EEG responses to TMS were significantly reduced in patients with either BPD, MDD or SCZ (range 11-27 Hz; one-way ANOVA: $F=12.31 ; \mathrm{d} f=3,44 ; p=0.000006$ ) (Fig. 1c). Frontal natural frequencies were markedly faster in healthy subjects compared to all the patient groups (post-hoc: $p=0.000485$ vs SCZ, $p=0.000171$ vs MDD, and $p=0.000290$ vs BP, respectively), which did not significantly differ among themselves.

Correlational analyses between natural frequencies and HDRS, PANSS scores and medication doses did not show significant effects.

\section{Discussion}

This is the first study to provide a TMS/EEG direct measure of frontal natural oscillations in patients with either BPD or MDD, compared to HC and SKZ. We extended the finding of reduced gamma oscillations, previously reported in SCZ, to mood disorders. All the three diagnostic conditions were associated with significantly slower gamma-band oscillations compared to healthy controls, and did not differ among themselves.

Common to these psychiatric conditions, a biological underpinning of slower gamma-band oscillations could be found in abnormal $\Upsilon$-aminobutyric acid (GABA) neurotransmission.

TMS/EEG can assess cortical inhibition due to inhibitory GABA interneurons (Daskalakis et al., 2002b), and short cortical inhibition, interhemispheric inhibition and cortical silent period are decreased in SCZ (Daskalakis et al., 2002a; Fitzgerald and Daskalakis, 2008), MDD (Lefaucheur et al., 2008; Levinson et al., 2010) and BPD (Levinson et al., 2007). Gamma oscillations may reflect the activity of GABA inhibitory interneurons (Brenner et al., 2009; Gonzalez-Burgos and Lewis, 2008; Gray and McCormick, 1996;
Traub et al., 2005), which produce and sustain complex large-scale network oscillations in fast frequency bands $(40-100 \mathrm{~Hz}$ ) (Benes and Berretta, 2001), also generating inhibitory potentials in excitatory pyramidal neurons (Whittington et al., 2011). GABAa receptor agonizts activate, and antagonists block, high frequency oscillations (Whittington et al., 1995). Fast parvalbumin-expressing GABA interneurons are necessary for high-frequency oscillations (Bartos et al., 2007; Uhlhaas et al., 2008), and recent animal studies demonstrated that their inhibition resulted in gamma suppression (Sohal et al., 2009). Similarly, decreasing fast-spiking interneuron activity reduced power and synchronization of gamma oscillations (Spencer, 2009), while its activation induced gamma power increase (Cardin et al., 2009).

GABA-ergic neurotransmission has been extensively studied in psychiatry (Basar, 2013). Post-mortem, low GABA levels were found in SCZ (Volk and Lewis, 2002) and MDD (Rajkowska et al., 2007), and the GABA-synthesizing enzyme GAD1 and GAD67 were altered in SCZ and BPD (Akbarian and Huang, 2006; GonzalezBurgos and Lewis, 2008). In depressed suicide victims GABAa receptor mRNA expression was reduced in hippocampus, amygdala and frontal cortex (Merali et al., 2004; Poulter et al., 2010). Reduced density of gabaergic neurons was found in the cortex of patients with either BPD or SCZ (Benes and Berretta, 2001), with reduced GABA synthesis in PV-interneurons (Lewis et al., 2005) in SCZ, suggesting a considerable overlap in inhibitory interneuron abnormalities in neuropsychiatric disorders. Brain magnetic resonance spectroscopy revealed low GABA levels in prefrontal cortex of patients with MDD (Hasler et al., 2007; Price et al., 2009) and BPD (Bhagwagar et al., 2007). Altogether, these data support the hypothesis that abnormal GABAergic neurotransmission could be critical to explain the abnormal $\Upsilon$-oscillations observed in our patients (Sohal et al., 2009; Whittington et al., 2000a).

GABAergic neurotransmission is a therapeutic target in mood disorders and in SCZ. GABA levels increase with mood-stabilizing 
medications such as valproate and lithium in BPD (Malhi et al., 2013; O'Donnell et al., 2003). High-frequency repetitive transcranial magnetic stimulation (rTMS) enhances GABA-inhibitory mechanisms (Daskalakis et al., 2006), and increases gammaoscillations in HC (Barr et al., 2009). Indeed, rTMS has been shown to improve cognitive deficits in MDD (Downar and Daskalakis, 2013) involving synaptic modulation and plasticity (Esser et al., 2006). Deficits in the modulations of the dopamine system may trigger the appearance of a defective GABA (Benes and Berretta, 2001). Recent studies reported that clozapine treatment may potentiate GABA receptors in schizophrenia patients (Liu et al., 2009).

However, patients with MDD and BPD showed reduced gamma activity even after complete remission (Ozerdem et al., 2011; Shaw et al., 2013), suggesting that successful treatment is unable to normalize these core biological features of the disorders. A recent study reported a deficit to produce frontal fast oscillations, independent of medication status (Minzenberg et al., 2010). Here we did not find any correlation between medication doses and natural frequencies. We also previously reported that the natural frequencies of different cortical areas, other than the frontal ones, were not altered in medicated SCZ patients, while if medications would affect neuronal oscillations one would expect a generalized effect (Ferrarelli et al., 2012).

Strengths of the present study include a focused research question, state-of-the-art TMS/EEG methods, and straightforward effects. However, our experimental setting did not allow to directly assess the role of deeper structures, such as hippocampus, which contribute to gamma oscillations (Basar et al., 2001). We obtained an excellent power to study group differences, but could not consider other biological markers, gene variants, and their interaction with clinical variables. Patients were non drug-naïve. Recruitment was in a single ethnic group, thus raising the possibility of population stratifications limiting the generalizability of the findings.

In conclusion, these limitations do not bias the main finding of significantly lower natural frequency of frontal cortico-thalamocortical circuits in patients with BPD, MDD, and SCZ, which suggest their possible relevance as an endophenotype common to major psychoses.

\section{Role of the funding source}

The authors declare no Funding Source for the present work.

\section{Conflict of interest}

None of the authors have financial disclosures or conflicts of interest pertinent to the contents of the manuscript.

\section{Acknowledgements}

We wish to thank Sara Poletti, Daniele Radaelli, Clara Locatelli, and Marta Bosia for their help.

\section{Appendix A. Supplementary material}

Supplementary data associated with this article can be found in the online version at: http://dx.doi.org/10.1016/j.jad.2015.05.043. http://dx.doi.org/10.1016/j.jad.2015.05.043

\section{References}

Akbarian, S., Huang, H.S., 2006. Molecular and cellular mechanisms of altered GAD1/GAD67 expression in schizophrenia and related disorders. Brain Res. Rev. 52, 293-304.

Barr, M.S., Farzan, F., Rusjan, P.M., Chen, R., Fitzgerald, P.B., Daskalakis, Z.J., 2009. Potentiation of gamma oscillatory activity through repetitive transcranial magnetic stimulation of the dorsolateral prefrontal cortex. Neuropsychopharmacology 34, 2359-2367.

Bartos, M., Vida, I., Jonas, P., 2007. Synaptic mechanisms of synchronized gamma oscillations in inhibitory interneuron networks. Nat. Rev. Neurosci. 8, 45-56.

Basar, E., 2013. Brain oscillations in neuropsychiatric disease. Dialogues Clin. Neurosci. $15,291-300$.

Basar, E., Guntekin, B., 2008. A review of brain oscillations in cognitive disorders and the role of neurotransmitters. Brain Res. 1235, 172-193.

Basar, E., Schurmann, M., Basar-Eroglu, C., Demiralp, T., 2001. Selectively distributed gamma band system of the brain. Int. J. Psychophysiol. 39, 129-135.

Benes, F.M., Berretta, S., 2001. Gabaergic interneurons. implications for understanding schizophrenia and bipolar disorder. Neuropsychopharmacology 25 $1-27$.

Bhagwagar, Z., Wylezinska, M., Jezzard, P., Evans, J., Ashworth, F., Sule, A., Matthews, P.M. Cowen, P.J., 2007. Reduction in occipital cortex gamma-aminobutyric acid concentrations in medication-free recovered unipolar depressed and bipolar subjects. Biol. Psychiatry 61, 806-812.

Brenner, C.A., Kieffaber, P.D., Clementz, B.A., Johannesen, J.K., Shekhar, A., O'Donnell, B.F., Hetrick, W.P., 2009. Event-related potential abnormalities in schizophrenia: a failure to "gate in" salient information? Schizophr. Res. 113, 332-338.

Buzsaki, G., Watson, B.O., 2012. Brain rhythms and neural syntax: implications for efficient coding of cognitive content and neuropsychiatric disease. Dialogues Clin. Neurosci. 14, 345-367.

Canali, P., 2014. A role for TMS/EEG in neuropsychiatric disorders. Neurol. Psychiatry Brain Res. 20, 37-40.

Cardin, J.A., Carlen, M., Meletis, K., Knoblich, U., Zhang, F., Deisseroth, K., Tsai, L.H., Moore, C.I., 2009. Driving fast-spiking cells induces gamma rhythm and controls sensory responses. Nature 459, 663-667.

Casali, A.G., Casarotto, S., Rosanova, M., Mariotti, M., Massimini, M., 2010. General indices to characterize the electrical response of the cerebral cortex to TMS Neuroimage 49, 1459-1468.

Cho, R.Y., Konecky, R.O., Carter, C.S., 2006. Impairments in frontal cortical gamma synchrony and cognitive control in schizophrenia. Proc. Natl. Acad. Sci. USA 103 19878-19883.

Daskalakis, Z.J., Christensen, B.K., Chen, R., Fitzgerald, P.B., Zipursky, R.B., Kapur, S. 2002a. Evidence for impaired cortical inhibition in schizophrenia using transcranial magnetic stimulation. Arch. Gen. Psychiatry 59, 347-354.

Daskalakis, Z.J., Christensen, B.K., Fitzgerald, P.B., Chen, R., 2002b. Transcranial magnetic stimulation: a new investigational and treatment tool in psychiatry. J. Neuropsychiatry Clin. Neurosci. 14, 406-415.

Daskalakis, Z.J., Moller, B., Christensen, B.K., Fitzgerald, P.B., Gunraj, C., Chen, R., 2006. The effects of repetitive transcranial magnetic stimulation on cortical inhibition in healthy human subjects. Exp. Brain Res. 174, 403-412.

Delorme, A., Makeig, S., 2004. EEGLAB: an open source toolbox for analysis of single-trial EEG dynamics including independent component analysis. J. Neurosci. Methods 134, 9-21.

Downar, J., Daskalakis, Z.J., 2013. New targets for rTMS in depression: a review of convergent evidence. Brain Stimul. 6, 231-240.

Esser, S.K., Huber, R., Massimini, M., Peterson, M.J., Ferrarelli, F., Tononi, G., 2006. A direct demonstration of cortical LTP in humans: a combined TMS/EEG study. Brain Res. Bull. 69, 86-94.

Ferrarelli, F., Massimini, M., Peterson, M.J., Riedner, B.A., Lazar, M., Murphy, M.J. Huber, R., Rosanova, M., Alexander, A.L., Kalin, N., Tononi, G., 2008. Reduced evoked gamma oscillations in the frontal cortex in schizophrenia patients: a TMS/EEG study. Am. J. Psychiatry 165, 996-1005.

Ferrarelli, F., Sarasso, S., Guller, Y., Riedner, B.A., Peterson, M.J., Bellesi, M., Massimini, M., Postle, B.R., Tononi, G., 2012. Reduced natural oscillatory frequency of frontal thalamocortical circuits in schizophrenia. Arch. Gen. Psychiatry 69, $766-774$.

Fitzgerald, P.B., Daskalakis, Z.J., 2008. A review of repetitive transcranial magnetic stimulation use in the treatment of schizophrenia. Can. J. Psychiatry 53, 567-576.

Gallinat, J., Winterer, G., Herrmann, C.S., Senkowski, D., 2004. Reduced oscillatory gamma-band responses in unmedicated schizophrenic patients indicate impaired frontal network processing. Clin. Neurophysiol. 115, 1863-1874.

Gonzalez-Burgos, G., Lewis, D.A., 2008. GABA neurons and the mechanisms of network oscillations: implications for understanding cortical dysfunction in schizophrenia. Schizophr. Bull. 34, 944-961.

Gray, C.M., McCormick, D.A., 1996. Chattering cells: superficial pyramidal neurons contributing to the generation of synchronous oscillations in the visual cortex. Science 274, 109-113.

Haig, A.R., Gordon, E., De Pascalis, V., Meares, R.A., Bahramali, H., Harris, A., 2000. Gamma activity in schizophrenia: evidence of impaired network binding? Clin. Neurophysiol. 111, 1461-1468.

Hasler, G., van der Veen, J.W., Tumonis, T., Meyers, N., Shen, J., Drevets, W.C., 2007 Reduced prefrontal glutamate/glutamine and gamma-aminobutyric acid levels in major depression determined using proton magnetic resonance spectroscopy. Arch. Gen. Psychiatry 64, 193-200. 
Herrmann, C.S., Demiralp, T., 2005. Human EEG gamma oscillations in neuropsychiatric disorders. Clin. Neurophysiol. 116, 2719-2733.

Hill, T., Lewicki, P., 2006. General linear models, StatSoft ed. Statistics: Methods and Applications: A Comprehensive Reference for Science, Industry, and Data Mining. StatSoft., Tulsa, OK, pp. 245-276.

Komssi, S., Savolainen, P., Heiskala, J., Kahkonen, S., 2007. Excitation threshold of the motor cortex estimated with transcranial magnetic stimulation electroencephalography. NeuroReport 18, 13-16.

Lee, P.S., Chen, Y.S., Hsieh, J.C., Su, T.P., Chen, L.F., 2010. Distinct neuronal oscillatory responses between patients with bipolar and unipolar disorders: a magnetoencephalographic study. J. Affect. Disord. 123, 270-275.

Kwon, J.S., O'Donnell, B.F., Wallenstein, G.V., Greene, R.W., Hirayasu, Y., Nestor, P.G., Hasselmo, M.E., Potts, G.F., Shenton, M.WE., McCarley, R.W, 1999. Gamma frequency-range abnormalities to auditory stimulation in schizophrenia. Arch Gen Psychiatry 56, 1001-1005.

Lefaucheur, J.P., Lucas, B., Andraud, F., Hogrel, J.Y., Bellivier, F., Del Cul, A., Rousseva, A Leboyer, M., Paillere-Martinot, M.L., 2008. Inter-hemispheric asymmetry of motor corticospinal excitability in major depression studied by transcranial magnetic stimulation. J. Psychiatr. Res. 42, 389-398.

Levinson, A.J., Fitzgerald, P.B., Favalli, G., Blumberger, D.M., Daigle, M., Daskalakis, Z.J. 2010. Evidence of cortical inhibitory deficits in major depressive disorder. Biol. Psychiatry 67, 458-464.

Levinson, A.J., Young, L.T., Fitzgerald, P.B., Daskalakis, Z.J., 2007. Cortical inhibitory dysfunction in bipolar disorder: a study using transcranial magnetic stimulation. J. Clin. Psychopharmacol. 27, 493-497.

Lewis, D.A., Hashimoto, T., Volk, D.W., 2005. Cortical inhibitory neurons and schizophrenia. Nat. Rev. Neurosci. 6, 312-324.

Light, Hsu, Hsieh, Meyer-Gomes, Sprock, Swerdlow, Braff, 2006. Gamma band oscillations reveal neural network cortical coherence dysfunction in schizophrenia patients. Biol Psychiatry, 1231-1240.

Liu, S.K., Fitzgerald, P.B., Daigle, M., Chen, R., Daskalakis, Z.J., 2009. The relationship between cortical inhibition, antipsychotic treatment, and the symptoms of schizophrenia. Biol. Psychiatry 65, 503-509.

Liu, T.Y., Hsieh, J.C., Chen, Y.S., Tu, P.C., Su, T.P., Chen, L.F., 2012. Different patterns of abnormal gamma oscillatory activity in unipolar and bipolar disorder patients during an implicit emotion task. Neuropsychologia 50, 1514-1520.

Maharajh, K., Abrams, D., Rojas, D.C., Teale, P., Reite, M.L., 2007. Auditory steady state and transient gamma band activity in bipolar disorder. Int. Congr. Ser. 1300, 707-710.

Malhi, G.S., Tanious, M., Das, P. Coulston, C.M., Berk, M., 2013. Potential mechanisms of action of lithium in bipolar disorder. Current understanding. CNS Drugs 27, 135-153.

Merali, Z., Du, L., Hrdina, P., Palkovits, M., Faludi, G., Poulter, M.O., Anisman, H., 2004. Dysregulation in the suicide brain: mRNA expression of corticotropinreleasing hormone receptors and GABA(A) receptor subunits in frontal cortical brain region. J. Neurosci. 24, 1478-1485.

Minzenberg, M.J., Firl, A.J., Yoon, J.H., Gomes, G.C., Reinking, C., Carter, C.S., 2010 Gamma oscillatory power is impaired during cognitive control independent of medication status in first-episode schizophrenia. Neuropsychopharmacology 35, 2590-2599.

Nikolic, D., Fries, P., Singer, W., 2013. Gamma oscillations: precise temporal coordination without a metronome. Trends Cogn. Sci. 17, 54-55.

O'Donnell, B.F., Hetrick, W.P., Vohs, J.L., Krishnan, G.P., Carroll, C.A., Shekhar, A., 2004a. Neural synchronization deficits to auditory stimulation in bipolar disorder. NeuroReport 15, 1369-1372.

O'Donnell, B.F., Vohs, J.L., Hetrick, W.P., Carroll, C.A., Shekhar, A., 2004b. Auditory event-related potential abnormalities in bipolar disorder and schizophrenia. Int. J. Psychophysiol. 53, 45-55.

O'Donnell, T., Rotzinger, S., Nakashima, T.T., Hanstock, C.C., Ulrich, M., Silverstone, P.H., 2003. Chronic lithium and sodium valproate both decrease the concentration of myoinositol and increase the concentration of inositol monophosphates in rat brain. Eur. Neuropsychopharmacol. 13, 199-207.

Ozerdem, A., Guntekin, B., Atagun, I., Turp, B., Basar, E., 2011. Reduced long distance gamma (28-48 Hz) coherence in euthymic patients with bipolar disorder. J. Affect. Disord. 132, 325-332.
Ozerdem, A., Guntekin, B., Saatci, E., Tunca, Z., Basar, E., 2010. Disturbance in long distance gamma coherence in bipolar disorder. Prog. Neuropsychopharmacol. Biol. Psychiatry 34, 861-865.

Poulter, M.O., Du, L., Zhurov, V., Palkovits, M., Faludi, G., Merali, Z., Anisman, H., 2010. Altered organization of GABA(A) receptor mRNA expression in the depressed suicide brain. Front. Mol. Neurosci. 3, 3.

Price, R.B., Shungu, D.C., Mao, X., Nestadt, P., Kelly, C., Collins, K.A., Murrough, J.W., Charney, D.S., Mathew, S.J., 2009. Amino acid neurotransmitters assessed by proton magnetic resonance spectroscopy: relationship to treatment resistance in major depressive disorder. Biol. Psychiatry 65, 792-800.

Rajkowska, G., O'Dwyer, G., Teleki, Z., Stockmeier, C.A., Miguel-Hidalgo, J.J., 2007. GABAergic neurons immunoreactive for calcium binding proteins are reduced in the prefrontal cortex in major depression. Neuropsychopharmacology 32, $471-482$.

Rodriguez, E., George, N., Lachaux, J.P., Martinerie, J., Renault, B., Varela, F.J., 1999 Perception shadow: long-distance synchronization of human brain activity. Nature 397, 430-433.

Rosanova, M., Casali, A., Bellina, V., Resta, F., Mariotti, M., Massimini, M., 2009. Natural frequencies of human corticothalamic circuits. J. Neurosci. 29, 7679-7685.

Rosanova, M., Casarotto, S., Pigorini, A., Canali, P., Casali, A.G., Massimini, M., 2012. Combining transcranial magnetic stimulation with electroencephalography to study human cortical excitability and effective connectivity. In: Fellin, T., Halassa, M. (Eds.), Neuronal Network Analysis - Concepts and Experimental Approaches. Springer, New York/Heidelberg, pp. 435-457.

Shaw, A., Brealy, J., Richardson, H., Muthukumaraswamy, S.D., Edden, R.A., John Evans, C., Puts, N.A., Singh, K.D., Keedwell, P.A., 2013. Marked reductions in visual evoked responses but not gamma-aminobutyric acid concentrations or gamma-band measures in remitted depression. Biol. Psychiatry 73, 691-698.

Sohal, V.S., Zhang, F., Yizhar, O., Deisseroth, K., 2009. Parvalbumin neurons and gamma rhythms enhance cortical circuit performance. Nature 459, 698-702.

Spencer, K.M., 2009. The functional consequences of cortical circuit abnormalities on gamma oscillations in schizophrenia: insights from computational modeling. Front. Hum. Neurosci. 3, 33.

Spencer, K.M., Salisbury, D.F., Shenton, M.E., McCarley, R.W., 2008. Gamma-band auditory steady-state responses are impaired in first episode psychosis. Biol. Psychiatry 64, 369-375.

Symond, M.P., Harris, A.W., Gordon, E., Williams, L.M., 2005. "Gamma synchrony" in first-episode schizophrenia: a disorder of temporal connectivity? Am. J. Psychiatry $162,459-465$.

Traub, R.D., Bibbig, A., LeBeau, F.E., Cunningham, M.O., Whittington, M.A., 2005. Persistent gamma oscillations in superficial layers of rat auditory neocortex: experiment and model. J. Physiol. 562, 3-8.

Uhlhaas, P.J., Haenschel, C., Nikolic, D., Singer, W., 2008. The role of oscillations and synchrony in cortical networks and their putative relevance for the pathophysiology of schizophrenia. Schizophr. Bull. 34, 927-943.

Uhlhaas, P.J., Singer, W., 2010. Abnormal neural oscillations and synchrony in schizophrenia. Nat. Rev. Neurosci. 11, 100-113.

Virtanen, J., Ruohonen, J., Natanen, R., Ilmoniemi, R.J., 1999. Instrumentation for the measurement of electric brain responses to transcranial magnetic stimulation. Med. Biol. Eng. Comput. 37, 322-326.

Volk, D.W., Lewis, D.A., 2002. Impaired prefrontal inhibition in schizophrenia: relevance for cognitive dysfunction. Physiol. Behav. 77, 501-505.

Whittington, M.A., Cunningham, M.O., LeBeau, F.E., Racca, C., Traub, R.D., 2011. Multiple origins of the cortical gamma rhythm. Dev. Neurobiol. 71, 92-106.

Whittington, M.A., Faulkner, H.J., Doheny, H.C., Traub, R.D., 2000a. Neuronal fast oscillations as a target site for psychoactive drugs. Pharmacol. Ther. 86, $171-190$.

Whittington, M.A., Traub, R.D., Jefferys, J.G., 1995. Synchronized oscillations in interneuron networks driven by metabotropic glutamate receptor activation. Nature 373, 612-615.

Whittington, M.A. Traub, R.D., Kopell, N., Ermentrout, B., Buhl, E.H., 2000b. Inhibition-based rhythms: experimental and mathematical observations on network dynamics. Int. J. Psychophysiol. 38, 315-336. 